\title{
PHÂN TÍCH CHI PHÍ PHẪU THUÂT Ổ BỤNG TAI BÊNNH VIÊN ĐẠI HỌC Y DƯỢC TP.HỒ CHÍ MINH VÀ BÊ̂NH VIỆN CHỢ RẪY THEO QUAN ĐIỂM NGƯỜI CHI TRẢ NĂM 2020
}

\author{
Ngô Thị Thảo Nguyên*, Nguyễn Thị Thu Thủy*
}

\section{TÓM TẮT}

Phẫu thuât (PT) đóng vai trò quan trọng trong hê thống chăm sóc sức khỏe, trong đó PT ổ bung là một trong những quy trình ngoại khoa phổ biển. Chi phí (CP) cho PT dần trở thành gánh nặng cho ngân sách y tế, trong đó $\mathrm{CP}$ dành cho $\mathrm{PT}$ ổ bung chưa được nghiên cứu đây đủ, đặc biệt là đối với các quốc gia có nguồn ngân sách y tế hạn hẹp như Việt Nam. Nghiên cứu phân tích CP PT ổ bụng được thực hiện tại bệnh viện Đại học Y Dược Thành phố Hồ Chí Minh - cơ sở 1 (BंV ĐHYD HCM) và bệnh viện Chợ Rẫy (BV CR) với thiết kế mô tả cắt ngang trên mẫu nghiên cứu gồm toàn bộ người bệnh PT ổ bụng thỏa tiểu chí chọn mẫu trong thời gian nghiên cứu từ tháng 10/2020 - 03/2021. CP được đánh giá trên quan điểm của người chi trả bao gồm $C P$ trực tiếp y tế, $C P$ trực tiếp ngoài y tế và $C P$ gián tiếp. Dữ liêu $\mathrm{CP}$ được thu thâp dựa trên phiếu thanh toán $\mathrm{CP}$ khám chữa bệnh, bảng kê $\mathrm{CP}$, phiếu khảo sát thông tin bênh nhân PT ổ bunng. Nghiên cứu trên 201 người bệnh PT ổ bụng tại BV ĐHYD HCM và BV CR ghi nhân tổng CP PT có giá trị trung vị 31,19 triệu VND (IQR: 23,92 triệu - 45,63 triệu VNĐ), trong đó $C P$ trực tiếp y tế chiếm ưu thế với giá trị trung vị 25,83 triệu VNĐ (IQR: 20,52 triệu - 39,22 triệu VNĐ), CP trực tiếp ngoài y tế - 1,03 triêu VNĐ (IQRR: 0,62 triệu - 1,84 triệu VNĐ), $\mathrm{CP}$ gián tiếp - 2,27 triệu VNĐ (IQR: 1,31 triểu - 4,09 triệu VNĐ). Nghiên cứu ghi nhận $\mathrm{CP}$ chi trả bởi người bệnh cao hơn $\mathrm{CP}$ chi trả bởi BHYT (70,23\% so với $29,77 \%$, tương ứng). Nghiên cứu các yếu tố liên quan nhằm dự báo $\mathrm{CP} P \mathrm{PT}$ và nghiên cứu tại các bệnh viện tuyến dưới cần được thực hiện trong tương lai nhằm hoàn thiên bức tranh đây đủ về CP PT tạo cơ sở đề xuất các giải pháp giảm thiểu gánh nặng kinh tế của can thiệp.

Từ khóa: phân tích CP, CP PT, PT ổ bụng

\section{SUMMARY \\ ANALYZE COST OF ABDOMINAL SURGERY AT UNIVERSITY MEDICAL CENTER HOCHIMINH CITY AND CHORAY HOSPITAL FROM PAYER'S PERSPECTIVE IN 2020}

Surgery takes important role in the healthcare system, from which abdominal surgery (AS) is one of the common surgical procedures. Surgery costs (SC) has become burden on the health budget, in which the cost for AS has not been fully studied, especially for countries with limited healthcare budget such as

*Trường Đại học Y Dược Thành phố Hồ Chí Minh Chịu trách nhiệm chính: Nguyễn Thị Thu Thủy Email: nguyenthuthuy@ump.edu.vn Ngày nhận bài: 23.8.2021

Ngày phản biện khoa học: 18.10.2021

Ngày duyệt bài: 25.10.2021
Vietnam. This study analyzes AS costs at University Medical Center HCMC (UMCH) and Cho Ray Hospital (CRH) with cross-sectional descriptive study on AS patients who met the selecting criteria from October 2020 to March 2021 at UMCH and CRH. Costs were assessed from the payer's perspective include direct medical costs, non-medical direct costs and indirect costs. Data is collected based on medical examination and treatment payment slips, cost statements, survey forms of AS. A study on 201 AS patients recorded that total SC has a median value of 31,19 million VND (IQR: 23,92 million - 45,63 million VND), in which direct medical costs dominated with median value of 25,83 million VND (IQR: 20,52 million - 39,22 million VND), non-medical direct costs - 1,03 million VND (IQR: 0,62 million - 1,84 million VND), indirect costs 2,27 million VND (IQR: 1,31 million - 4,09 million VND). The study found that the SC paid by patients was higher than the SC paid by health insurance $(70,23 \%$ vs $29,77 \%$, respectively). Research on related factors to forecast SC and research at lowerlevel hospitals should be carried out in the future in order to complete a full picture of SC, creating a basis for proposing solutions reduce the economic burden of the intervention.

Keywords: costs analysis, surgery costs, abdominal surgery

\section{I. ĐĂT VẤN ĐỀ}

Trên thế giới và ở Việt Nam, phẫu thuật (PT) chiếm tỷ lệ lớn và khổng thể thiếu trong hệ thống chăm sóc sức khỏe, trong đó PT ổ bụng là một trong những quy trình ngoại khoa phổ biến, được thực hiện thường xuyên nhất. Chi phí (CP) cho PT, gây mê, chăm sóc sau PT dân trở thành gánh nặng cho ngân sách y tế. Đối với các quốc gia có nguồn ngân sách y tế hạn hẹp như Việt Nam CP dành cho PT ổ bụng chưa được nghiên cứu đâyy đủ, mặc dù đã có một số nghiên cứu được công bố về CP PT viêm ruôtt thửa [2], cắt tử cung[1],... Vì vậy để ghi nhận bức tranh toàn diện về CP PT ổ bụng tạo cơ sở tối ưu hóa nguồn lực y tế, nghiên cứu phân tích chi phí phẫu thuật ổ bụng được thực hiện với các mục tiêu chính sau đây:

- Khảo sát đặc điểm người bệnh PT ổ bụng tại bênh viện (BV) Đại học Y Dược (ĐHYD) thành phố Hồ Chí Minh (TPHCM) - CS1 và bệnh viện Chơ Rẫy.

- Khảo sát CP PT ổ bụng theo quan điêm người chi trả tại bệnh viện Đại học Y Dước TPHCM - CS1 và bệnh viện Chỡ Rẫy. 


\section{II. ĐỐI TƯỢNG VÀ PHƯƠNG PHÁP NGHIÊN CỨU}

Đối tượng nghiên cứu. Chi phí phẫu thuật ổ bụng tại bệnh viện Đại học Y Dược thành phố Hồ Chí Minh và bệnh viện Chợ Rẫy.

\section{Phương pháp nghiên cứu}

Mẫu nghiên cứu. Toàn bô hồ sơ bênh án và người bệnh điều trị phẫu thuật ổ bụng tại BV ĐHYD HCM và $B V C R$ phù hợp với các tiêu chí lựa chọn và không vi phạm tiều chí loại trừ trong thời gian nghiên cứu từ tháng 10/2020 - 3/2021.

- Tiêu chí lưa chon: Người bệnh PT và hồ sơ bệnh án của người bệnh PT ổ bụng tại BV ĐHYD HCM và $B V$ CR; người bệnh đồng ý tham gia nghiên cứu.

- Tiêu chí loại trừ: Bệnh nhân ngắt quãng thời gian điều trị do tự ý xuất viện hoặc chuyển viện; hồ sơ bệnh án không đầy đủ thông tin cần thu thập.

Biến số nghiên cứu. Nghiên cứu tiến hành khảo sát CP PT ổ bụng thông qua các biến số nghiên cứu về $\mathrm{CP} P \mathrm{PT}^{\text {ô }}$ bụng và đặc điểm người bệnh bao gồm đặc điểm nhân khẩu học (giới tính, tuổi, miền, khu vực sinh sống, nơi ở, dân tộc, nghề nghiệp, trình độ học vấn, mức thu nhập) và đặc điểm bệnh lý (mức BHYT chi trả, vị trí PT, phương pháp PT, loại PT, tăng huyết áp, tiểu đường, bệnh kèm theo, thời gian PT, số ngày nằm viện).

CP của người bệnh PT ổ bụng được tính như sau: TCP = CP TTYT + CP TTNYT + CPGT

(TCP: tổng chi phí; CP TTYT: chi phí trực tiếp y tế; CP TTNYT: chi phí trực tiếp ngoài y tế; $C P$
GT: chi phí gián tiếp)

CP TTYT gồm CP thuốc, vật tư tiêu hao, CP nhân công, CP phòng PT và phòng hồi tỉnh, thu thập từ dữ liệu thanh toán dựa trên hồ sơ bệnh án và phiếu thanh toán $C P$ khám chữa bệnh của mỗi người. CP TTNYT gồm CP di chuyển, $\mathrm{CP}$ ăn uống, CP ở trọ, CP thăm nuôi, CP GT là thu nhập mất đi của người bênh, thu nhâp mất đi của người thân. $\mathrm{CP}$ TTNYT và $\mathrm{CP}$ GT thu thập từ dữ liệu phỏng vấn người bệnh theo phiếu khảo sát thông tin bệnh nhân PT ổ bụng tại BV ĐHYD $\mathrm{HCM}$ và $\mathrm{BV} C \mathrm{CR}$.

Thời gian và địa điểm nghiên cứu. Nghiên cứu được thực hiện tại $\mathrm{BV}$ ĐHYD HCM và $\mathrm{BV} C R$, thời gian từ tháng 10/2020 đến tháng 3/2021.

Thống kê và xử lý số liệu. Số liệu được thống kê và xử lý bằng phần mềm SPSS với độ tin cậy $95 \%$ với các phép kiểm thống kê phù hợp. Biến số định danh được thống kê bằng tần số (tỷ lệ \%), biến số định lượng được thống kê thông qua giá trị trung bình (độ lệch chuẩn/ khoảng tin cậy); trung vị (khoảng tứ phân vị (IQR)). Số liệu được trình bày dưới dạng hình và bảng.

\section{KẾT QUẢ NGHIÊN CỨU}

Đặc điểm người bệnh PT ổ bụng tại bệnh viện nghiên cứu. Thống kê và phẩn tích dữ liệu trển mẩu nghiên cứu gồm 201 người bệnh PT ồ bụng, nghiên cứu ghi nhận đặc điểm nhân khẩu và bệnh lý của mẫu được trình bày trong bảng 1 và 2.

Bảng 1. Đặc điểm nhân khẩu của người bệnh PT ổ bụng

\begin{tabular}{|c|c|c|c|c|c|}
\hline \multicolumn{2}{|r|}{ Đăc điếm } & N (\%) & \multicolumn{2}{|r|}{ Đăc điếm } & N (\%) \\
\hline \multirow{2}{*}{ Giới tính } & Nũ̃ & $93(46,27)$ & \multirow{8}{*}{$\begin{array}{l}\text { Nghề } \\
\text { nghiệp }\end{array}$} & NLE் thuộc CS công lập & $23(11,44)$ \\
\hline & Nam & $108(53,73)$ & & NLĐ thuộc CS nước ngoài & $5(2,49)$ \\
\hline \multirow{2}{*}{ Miên } & Trung & $54(26,87)$ & & $\begin{array}{l}\text { NLE thuộc CS tư nhân trong } \\
\text { nước }\end{array}$ & $37(18,41)$ \\
\hline & Nam & $147(73,13)$ & & NLĐ tai hô gia đình & $32(15,92)$ \\
\hline \multirow{3}{*}{$\begin{array}{l}\text { Khu vực } \\
\text { sinh sổng }\end{array}$} & Thành thị & $96(47,76)$ & & NLĐ tư do & $34(16,92)$ \\
\hline & Nông thôn & $73(36,32)$ & & Nghỉ hưu/ người cao tuối & $47(23,38)$ \\
\hline & Ngoại thành & $32(15,92)$ & & Nội trợ/ thất nghiệp & $12(5,97)$ \\
\hline \multirow{2}{*}{ TPHCM } & Ngoài TPHCM & $166(82,59)$ & & *Khác & $11(5,47)$ \\
\hline & TPHCM & $35(17,41)$ & \multirow{4}{*}{$\begin{array}{l}\text { Trình độ } \\
\text { học vấn }\end{array}$} & Dưới TPHT & $53(26,37)$ \\
\hline \multirow{6}{*}{$\begin{array}{c}\text { Thu nhập } \\
\text { trung } \\
\text { bình }\end{array}$} & Không có thu nhập & $35(17,41)$ & & THPT & $54(26,87)$ \\
\hline & Dưới 1 triệu & $9(4,48)$ & & Trung cấp/ cao đắng & $46(22,89)$ \\
\hline & Từ 1 đến dưới 5 triệu & $28(13,93)$ & & Đại học/ Sau đại học & $48(23,88)$ \\
\hline & Từ 5 đến dưới 10 triệu & $60(29,85)$ & \multirow{4}{*}{$\begin{array}{l}\text { Mức chi } \\
\text { trả BHYT }\end{array}$} & khồng có BHYT & $28(13,93)$ \\
\hline & Từ 10 đến dưới 20 triệu & $43(21,93)$ & & $80 \%$ & $150(74,63)$ \\
\hline & Từ 20 triêu trở lên & $26(12,94)$ & & $95 \%$ & $8(3,98)$ \\
\hline \multirow{4}{*}{ Tôn giáo } & Khồng & $99(49,25)$ & & $100 \%$ & $15(7,46)$ \\
\hline & Phật giáo & $70(34,83)$ & \multirow{3}{*}{ Dân tộc } & Kinh & $194(96,52)$ \\
\hline & Thiên chúa giáo & $29(14,43)$ & & Khác & $7(3,48)$ \\
\hline & Cao đài & $3(1,49)$ & & & \\
\hline
\end{tabular}




\begin{tabular}{|c|c|c|c|c|c|}
\hline & $\mathbf{N}$ & Nhỏ nhất & Lớn nhất & Trung bình & $\begin{array}{c}\text { Độ lệ̂̉ch } \\
\text { chuẩn }\end{array}$ \\
\hline Tuối & 201 & 16 & 84 & 51,26 & 14,83 \\
\hline
\end{tabular}

Ghi chú: *Khác: làm nông, học sinh, sinh (52\%). Nhóm người nghỉ hưu/cao tuối chiếm tỳ viên; THPT: trung học phổ thông; NLĐ: người lao lệ cao nhất $(23,38 \%)$, các nhóm trình độ học động; TPHCM: Thành phố Hồ Chí Minh; CS: ơ sở

Theo bảng 1 , nghiên cứu ghi nhận mẫu nghiên cứu có tỷ lệ nam: nữ là 1,16:1 với độ tuổi trung bình $51,26 \pm 14,83$ và dao động từ 16 tuổi đến 84 tuổi. Đa số người bệnh ở miền Nam (73,13\%) với khu vực sinh sống phổ biến nhất là thành thị $(47,76 \%)$ và ngoài TPHCM $(82,59 \%)$. Đa số người bệnh thuộc nhóm dân tộc Kinh vấn có tỷ lệ gần tương đương nhau và dao động từ $22,89 \%$ (trung cấp/cao đẳng) đến $26,87 \%$ (trình độ THPT). Nhóm thu nhập từ 5 triệu VND đến 10 triệu VNĐ chiếm tỷ lệ cao nhất $(29,85 \%)$, thấp nhất là nhóm dưới 1 triệu $(4,48 \%)$. Trong mẫu nghiên cứu $86,07 \%$ người bệnh có tham gia BHYT, trong đó đa số ở mức chi trả BHYT $80 \%$ (chiếm 74,63\%).

Bảng 2. Đặc điểm bênh lý của người bệnh PT ổ bụng

\begin{tabular}{|c|c|c|c|c|c|}
\hline \multicolumn{2}{|c|}{ Đặc điếm } & $N(\%)$ & \multicolumn{2}{|c|}{ Đặc điếm } & $N(\%)$ \\
\hline \multirow{3}{*}{ Vị trí PT } & Hệ gan mật tụy & $149(74,13)$ & \multirow{3}{*}{ Loại PT } & Loại I & $89(44,28)$ \\
\hline & Hệ tiêu hóa & $44(21,89)$ & & Loại II & $4(1,99)$ \\
\hline & Khác & $8(3,98)$ & & Đăc biêt & $108(53,73)$ \\
\hline \multirow{3}{*}{ Phương pháp PT } & Mố hở & $89(44,28)$ & \multirow{3}{*}{ ASA } & $\mathrm{I}$ & $80(39,80)$ \\
\hline & Nô̂i soi & $101(50,25)$ & & II & $75(37,31)$ \\
\hline & Kết hợp & $11(5,47)$ & & III & $46(22,89)$ \\
\hline \multirow{2}{*}{ Có bệnh kèm } & Không & $86(42,78)$ & \multirow{2}{*}{$\begin{array}{c}\text { Tăng huyết } \\
\text { áp }\end{array}$} & Không & $151(75,12)$ \\
\hline & Có & $115(57,22)$ & & Có & $50(24,88)$ \\
\hline \multirow{3}{*}{ Tiểu đường } & Không & $176(87,56)$ & \multirow{2}{*}{$\begin{array}{l}\text { Bệnh kèm } \\
\text { khác }\end{array}$} & Không & $124(61,69)$ \\
\hline & Có & $25(12,44)$ & & Có & $77(38,31)$ \\
\hline & $\mathbf{N}$ & Nhỏ nhất & Lớn nhất & GTTB & $\begin{array}{l}\text { Đồ lệ̂ch } \\
\text { chuẩn }\end{array}$ \\
\hline Thời gian PT (phút) & 201 & 40 & 220 & 115,43 & 48,03 \\
\hline $\begin{array}{l}\text { Số ngày nằm viện } \\
\text { (ngày) }\end{array}$ & 201 & 2 & 30 & 7,17 & 4,38 \\
\hline
\end{tabular}

*BHYT: bảo hiểm y tế; GTTB: giá trị trung bình; ASA: American Society of Anesthesiologist; khác: bẹn, phúc mạc, hậu môn)

Theo bảng 2, PT tại hệ gan mật tụy chiếm đa số với $74,1 \%$; tiếp đến là hê tiêu hóa $(21,9 \%)$; PT ở các vị trí khác chiếm tỷ lê thấp nhất $(3,98 \%)$. Đa số ca PT trong mẩu sử dụng phương pháp PT nội soi $(50,25 \%)$ và $\mathrm{PT}$ mổ hở $(44,28 \%)$, PT kết hợp chiếm tỳ lệ thấp nhất $(5,47 \%)$. PT loại đặc biệt chiếm tỷ lệ cao nhất $(53,73 \%)$, tiếp theo là loại I $(44,28 \%)$ và loại II chiếm tỷ lệ thấp nhất $(1,99 \%)$. Nghiên cứu ghi nhận $57,22 \%$ người bệnh mắc bệnh kèm, trong đó $12,44 \%$ mắc bệnh tiểu đường; $24,88 \%$ - tăng huyết áp. Đánh giá ASA ghi nhận người bênh ở mức I và II chiếm tỷ lệ tương đương (39,80\% và 37,31\%; tương ứng); người bệnh ở mức III chiếm tỳ lệ thấp nhất $(22,89 \%)$. Thời gian PT trung bình của mẫu nghiên cứu là $115,43 \pm$ 48,03 phút và dao động từ 40 phút đến 220 phút. Số ngày nằm viện trung bình là $7,17 \pm$ 4,38 ngày và dao động từ 2 đên 30 ngày.

\section{Phân tích CP PT ổ bung}

Phân tích CP PT ổ bụng theo giá trị. Khảo sát mẫu nghiên cứu gồm 201 người bệnh PT ô bụng tại các bệnh viện nghiên cứu, đề tài ghi nhận CP PT ổ bụng được trình bày trong bảng 3 .

Bảng 3. CP của người bệnh PT ổ bụng

\begin{tabular}{|c|c|c|c|c|c|c|}
\hline $\begin{array}{c}\text { Đơn vị } \\
\text { (triệu VNĐ) }\end{array}$ & $\begin{array}{l}\text { Trung } \\
\text { vi }\end{array}$ & $\begin{array}{l}\text { Ḱhoảng tứ } \\
\text { phân vị }\end{array}$ & GTTB & $\begin{array}{l}\text { Đố lệ̂̉ hh } \\
\text { chuẩn }\end{array}$ & $\begin{array}{l}\text { Tỷ lệ } \\
\text { \% }\end{array}$ & GTNN - GTLN \\
\hline Tống CP TTYT & 25,83 & $20,52-39,22$ & 36,52 & 25,64 & & $15,46-141,81$ \\
\hline Khám bệnh & 0,00 & $0,00-0,75$ & 0,38 & 0,56 & 1,03 & $0-3,25$ \\
\hline Ngày giường & 3,27 & $2,60-7,89$ & 6,41 & 6,42 & 17,56 & $3-30,36$ \\
\hline & & & & 2,41 & 9,16 & \\
\hline Chẩn đọ & 0,00 & 0,00 & 1,1 & 2,13 & 3,01 & 11,00 \\
\hline Thủ thuật PT & 12,70 & $11,12-13,85$ & 13,32 & 4,66 & 36,50 & $3,81-39,37$ \\
\hline
\end{tabular}




\begin{tabular}{|c|c|c|c|c|c|c|}
\hline Máu & 0,00 & $0,00-0,00$ & 0,43 & 1,28 & 1,17 & $0,00-10,00$ \\
\hline Thuốc Dịch truyền & 3,42 & $1,13-6,50$ & 5,20 & 6,41 & 14,23 & $0,23-43,01$ \\
\hline Vât tư y tế & 1,53 & $0,40-6,52$ & 5,53 & 9,47 & 15,16 & $0,07-47,56$ \\
\hline Dịch vụ y tế khác & 0,66 & $0,45-0,92$ & 0,79 & 0,60 & 2,17 & $0,15-5,88$ \\
\hline Tống CP TTNYT & 1,03 & $0,62-1,84$ & 1,63 & 1,92 & & $0,00-15,00$ \\
\hline CP di chuyến & 0,50 & $0,20-0,95$ & 0,92 & 1,35 & 56,44 & $0,00-8,00$ \\
\hline CP ăn uống & 0,40 & $0,00-0,80$ & 0,61 & 1,07 & 37,42 & $0,00-11,00$ \\
\hline CP ở tro & 0,00 & $0,00-0,00$ & 0,05 & 0,30 & 3,07 & $0,00-3,00$ \\
\hline CP thăm nuôi & 0,00 & $0,00-0,00$ & 0,05 & 0,36 & 3,07 & $0,00-3,40$ \\
\hline Tống CP GT & 2,27 & $1,31-4,09$ & 3,17 & 3,06 & & $0,00-17,50$ \\
\hline CP mất đi của người bệnh & 0,00 & $0,00-1,88$ & 1,32 & 2,38 & 41,62 & $0,00-14,77$ \\
\hline CP mất đi của người thân & 1,36 & $0,45-2,27$ & 1,85 & 2,13 & 58,38 & $0,00-12,27$ \\
\hline Tống CP & 31,19 & $23,92-45,63$ & 41,33 & 26,86 & & $16,77-146,60$ \\
\hline Tống CP TTYT & 25,83 & $20,52-39,22$ & 36,52 & 25,64 & 88,36 & $15,46-141,81$ \\
\hline Tổng CP TTNYT & 1,03 & $0,62-1,84$ & 1,63 & 1,92 & 3,94 & $0,00-15,00$ \\
\hline Tổng CP GT & 2,27 & $1,31-4,09$ & 3,17 & 3,06 & 7,70 & $0,00-17,50$ \\
\hline
\end{tabular}

GTTB: giá trị trung bình; $\mathrm{KTC}$ : khoảng tin đến là $\mathrm{CP}$ ăn uống $(37,42 \%)$, các $\mathrm{CP}$ khác không cậy; GTNN - GTLN: giá trị nhỏ nhất - lớn nhất

Theo bảng 3, nghiên cứu ghi nhận CP TTYT giá trị trung vị 25,83 triệu VNĐ (IQR: 20,52 triệu - 39,22 triệu VNE) và dao động từ 15,46 triệu đến 141,81 triệu VNĐ. Trong cấu phần CP TTYT, $\mathrm{CP}$ thủ thuật PT chiếm tỷ lệ cao nhất $(36,50 \%)$, tiếp theo là $\mathrm{CP}$ ngày giường $(17,56 \%)$, $\mathrm{CP}$ vật tư $y$ tế $(15,16 \%)$, CP thuốc dịch truyền $(14,23 \%)$, các $\mathrm{CP}$ còn lại không đáng kể và dao động từ $1,03 \%$ đến $9,16 \%$.

CP TTNYT có giá trị dao động từ 0 đến 15 triệu VNĐ với giá trị trung vị 1,03 triệu VND (IQR: 0,62 triệu - 1,84 triệu VNĐ). Về cấu phần, CP di chuyển chiếm tỷ lệ cao nhất $(56,44 \%)$, tiếp đáng kể $(3,07 \%)$.

CP GT có giá trị dao động từ 0 đến 17,5 triệu VNĐ, giá trị trung vị 2,27 triệu VNĐ (IQR: 1,31 triệu - 4,09 triệu VNĐ). Trong đó, $\mathrm{CP}$ mất đi của người thân chiếm tỷ lệ cao hơn $\mathrm{CP}$ mất đi của người bệnh (58,38\% so với 41,62\%; tương ứng).

Như vậy tổng CP có giá trị dao động từ 16,77 triệu đến 146,60 triệu VND với giá trị trung vị 31,19 triệu VND (IQR: 23,92 triệu - 45,63 triệu VNĐ). Trong đó $C P$ TTYT chiếm tỷ lệ cao nhất (88,37\%), CP GT và CP TTNYT chiếm tỷ lệ không đáng kể với $7,68 \%$ và 3,95\% tương ứng.

Phân tích CP PT ổ bung theo nguồn chi trả. Phân tích CP PT ổ bụng theo nguồn chi trả đề tài ghi nhận kết quả trình bày trong bảng 4 .

Bảng 4. CP của người bênh PT ổ bung theo nguồn chi trả

\begin{tabular}{|c|c|c|c|c|c|c|c|}
\hline \multicolumn{2}{|c|}{ Đơn vị (triệu VNĐ) } & $\begin{array}{c}\text { Trung } \\
\text { vị }\end{array}$ & $\begin{array}{c}\text { Khoảng tứ } \\
\text { phân vị }\end{array}$ & GTTB & ĐLC & $\begin{array}{c}\text { Tỷ lệ } \\
\text { \% }\end{array}$ & GTNN - GTLN \\
\hline $\begin{array}{c}\text { Mấu } \\
\text { nghiên } \\
\text { cứu }\end{array}$ & Tống CP & 31,19 & $23,93-45,51$ & 41,33 & 26,86 & 100,00 & $16,77-146,60$ \\
\cline { 2 - 8 } & BHYT chi trả & 12,06 & $3,90-18,25$ & 12,30 & 10,51 & 29,77 & $0,00-46,25$ \\
\cline { 2 - 8 } & NB chi trả & 20,76 & $15,66-34,86$ & 29,02 & 22,03 & 70,23 & $5,05-132,95$ \\
\hline
\end{tabular}

GTTB: giá trị trung bình; KTC: khoảng tin cậy; GTNN - GTLN: giá trị nhỏ nhất - lớn nhất, NB: người bệnh. Theo bảng 4, nghiên cứu ghi nhận CP do người bệnh chi trả có giá trị trung vị (20,76 triệu VND; IQR: 15,66 triệu - 34,86 triệu VNĐ), giá trị này cao hơn so với quỹ BHYT chi trả (2,06 triệu VND; IQR: 3,90 triệu - 18,25 triệu $\mathrm{VND}$ ). Trong tổng $\mathrm{CP}, \mathrm{CP}$ do người bệnh chi trả chiếm tỷ lệ cao hơn so với quỹ BHYT (70,23 \% và 29,77\%; tương ứng).

\section{BÀN LUÂ̂N}

Nghiên cứu tiến hành tại BV ĐHYD HCM và BV CR ghi nhận CP PT ổ bụng có giá trị trung vị 31,19 triệu VND (IQR: 23,92 triệu - 45,63 triệu VNĐ), trong đó CP TTYT chiếm tỷ lệ cao gấp 7,6 lần so với $\mathrm{CP}$ TTNYT và $\mathrm{CP} G \mathrm{GT}, \mathrm{CP} P \mathrm{PT}$ thủ thuật chiếm tỷ lệ cao nhất (chiếm hơn 1/3 CP TTYT), cao gấp đồi so với $\mathrm{CP}$ thuốc dịch truyền. Trong toàn mẫu nghiên cứu, $\mathrm{CP}$ do người bệnh chi trả chiếm tỷ lệ cao hơn CP do quỹ BHYT chi trả, BV ĐHYD HCM cũng có cấu trúc tương tự, BV CR có sự khác biệt với CP do quỹ BHYT chi trả chiếm tỷ lệ cao hơn.

Nghiên cứu được tiến hành taii BV ĐHYD HCM và $B V C R$, với tỷ lệ nam cao hớn nữ, tuổi trung bình của mẫu nghiên cứu là $51,26 \pm 14,83$ tuổi, điều này phù hợp với đặc điểm nhân khẩu của nghiên cứu của Trần Anh Vũ [5] và Nguyễn Toàn Thắng [3] về đặc điểm người bệnh PT ổ bụng. Đa số mẩu nghiên cứu ở miền Nam, điều này 
phù hợp với vị trí của BV ĐHYD HCM và $B V C R$. Mặt khác vì đây những bệnh viện tuyến cuối, mẫu nghiên cứu đa số thuộc nhóm ngoài TPHCM. Đối với người bênh có khả năng lao động, nhóm thuộc các cơ sở lao động tại nhà nước thấp, tập trung chủ yếu ở các cơ sở lao động ngoài nhà nước (tư nhân trong nước, hộ gia đình, tự do), điều này phù hợp với đặc điểm loại hình kinh tế ở Việt Nam [4]. Loại PT chủ yếu là $\mathrm{PT}$ loại đặc biệt và loại $\mathrm{I}$, điều này phù hợp vì đặc điểm của 2 bệnh viện tiến hành nghiên cứu là bệnh viện tuyến cuối nên các ca bệnh có tình trạng nặng và phức tạp hơn. Thời gian PT và số ngày nằm viện tương đương với nghiên cứu về PT bung của Koh. F. H. và cộng sự [7].

Tổng CP PT ổ bunng có giá trị trung bình cao gấp 6,11 lần so với giá trị trung bình của CP PT viêm ruột thừa trong nghiên cứu của Nguyễn Hữu Từ [2] và cao gấp 8,63 lần so với nghiên cứu của Trần Quốc Cường [6] về PT ở khoa ngoại khi quy đổi về cùng thời điểm. Về cấu trúc, CP TTYT chiếm tỷ lê cao hơn so với $C P$ GT và $C P$ TTNYT. Trong CP TTYT, CP cho PT thủ thuât chiếm tỷ lệ cao nhất tương tự nghiên cứu của Nguyễn Hữu Từ [2]. Mẫu nghiên cứu có nguồn chi trả từ người bệnh cao hơn so với quỹ BHYT, nguyên nhân có thể do một số dụng cụ y tế, xét nghiệm, dụng cụ hỗ trợ dùng trong phâuu thuật thường khổng được BHYT chi trả.

Nghiên cứu phân tích về tổng CP PT bụng chung, hiện tại chưa có nghiên cứu tương tự đánh giá về CP PT tại Việt Nam, ngoài ra CP TTYT, nghiên cứu còn đánh giá được CP TTNYT và $\mathrm{CP}$ GT. Nghiên cứu còn hạn chế chỉ thực hiện tại 2 bệnh viện ở miền Nam và là bệnh viện tuyến cuối, nên đa số chỉ định PT nặng, chưa thể hiện được CP PT của các miền khác và các chỉ định nhẹ hơn ở bệnh viện tuyến dưới.

\section{KẾT LUÂN}

Tổng CP PT ổ bung có giá trị trung vị 31,19 triệu VND (IQR: 23,92 triệu - 45,63 triẹu VNĐ) với $\mathrm{CP}$ trực tiếp y tế chiếm đa số và $\mathrm{CP}$ tiền túi của người bênh cao hơn quỹ BHYT chi trả. Nghiên cứu các yếu tố liên quan nhằm dự báo CP PT và nghiên cứu tại các bệnh viện tuyến dưới cần được thực hiện trong tương lai nhằm hoàn thiên bức tranh đầy đủ về CP PT tao cơ sở đề xuất các giải pháp giảm thiểu gánh nặng kinh tế của can thiệp.

\section{TÀI LIÊU THAM KHẢO}

1. Lê Thị Hòa (2013), "Đánh giá kết quả phẫu thuâtt cắt tử cung toàn phần qua đường âm đạo và nội soi ở bệnh lý tử cung không sa", Tạp chí Phụ Sản.

2. Nguyển Hữu Từ (2019), "Phân tích chi phí điều trị viêm ruột thừa tại Bệnh viện đa khoa tỉnh Đắc Lắc", Jạp chí Y học Việt Nam. 479, pp. 212-216.

3. Nguyển Toàn Thắng (2016), "Đánh giá hiệu quả giảm đau sau phẩu thuật bụng và tác dụng không mong muốn của Fentanyl, Morphin, MorphinKetamin tĩnh mạch theo phương pháp bệnh nhân tư kiểm soát", Đai hoc $Y$ Hà Nôii.

4. Tổng cực Thống kề (2020), Niên giám thống kê, Nhà xuất bản Thống kê.

5. Trần Anh Vũ (2020), "Hiêuu quả của liệu pháp âm nhạc đối với lo lắng trước phẩu thuật ở bệnh nhân phẫu thuât ổ bung tại Bênh viện TW Thái Nguyên", Tạp chí Khoa học \& Công nghệ ĐHTN. 225, pp. $66^{-}-71$.

6. Trân Quốc Cường (2015), Nghiên cứu chi phí điều trị của người bệnh phẩu thuật tại Bệnh viện Quân Thủ Đức Thành phố Hồ Chí Minh năm 2013.

7. Koh F. H. et al. (2013), "Laparoscopic versus an open colectomy in an emergency setting: A casecontrolled study", Annals of Coloproctology. 29 (1), pp. 12-16.

\section{CÁC CHỦNG VI NẤM NGOÀI DA PHÂN LÂP ĐƯỢC VÀ ĐÔ̂ NHAY CẢM VỚI CÁC THUỐC KHÁNG NẤM HIÊN NAY TRÊN BỀNH NHẦN ĐẾN KHÁM TẠI BÊ̂NH VIỆN DA LIỄU THÀNH PHỐ HỒ CHÍ MINH NĂM 2021}

\section{TÓM TẮT}

\footnotetext{
${ }^{1}$ Đại học Y Dược TP.Hồ Chí Minh

²Bệnh viện Nguyễn Trãi

Chịu trách nhiệm chính: Tăng Tuấn Hải

Email: haitt@pnt.edu.vn

Ngày nhận bài: 23.8.2021

Ngày phản biện khoa học: 22.10.2021

Ngày duyệt bài: 2.11.2021
}

\section{Tăng Tuấn Hải ${ }^{1}$, Trần Phủ Mạnh Siêu ${ }^{1,2}$, Ngô Quốc Đạt ${ }^{1}$}

Đặt vấn đề: Nhiễm vi nấm ngoài da (dermatophytosis) là môtt trong những bênh phổ biến và khó điều trị. Vấn đề chẩn đoán tác nhân gây bệnh chưa được quan tâm triệt để, cộng với tình trạng kháng thuốc ngày càng tăng. Do đó cần thiết phải có nghiên cứu khảo sát các chủng vi nấm ngoài da hiện đang lưu hành trên các bệnh nhân đến khám tại bệnh viên $\mathrm{Da}$ Liễu, từ đó có cơ sở chẩn đoán và điều trị hiệu quả. Mục tiêu: Phân lập, định danh và tìm hiểu tỷ lệ của các chủng vi nấm ngoài da. Khảo sát độ nhạy cảm với các thuốc khám nấm hiện nay trên các bệnh 